\title{
Current Status of Knowledge and Research Perspectives in Korean Pear Genomics
}

\author{
Youngjae $\mathrm{Oh}^{1,2}$, Yoon-Kyeong $\mathrm{Kim}^{3}$, Daeil $\mathrm{Kim}^{1,2} *$ \\ ${ }^{1}$ Department of Horticulture, Chungbuk National University, Cheongju 28644, Korea \\ ${ }^{2}$ Brain Korea 21 Center for Bio-Resource, Chungbuk National University, Cheongju 28644, Korea \\ ${ }^{3}$ Pear Research Institute, National Institute of Horticultural \& Herbal Science, Rural Development Administration, Naju 58216, Korea
}

\begin{abstract}
The pear (Pyrus spp.) is most important fruit crop in the world. The genus Pyrus belongs to the subfamily Maloideae in the Rosaceae family and contains at least 22 primary species; however, only a few species, including $P$. pyrifolia, $P$. ussuriensis, $P$. bretschneideri, and P. communis have been utilized for fruit production. In Korea, awareness of the importance of the fruit industry and fruit tree breeding is low, and there is little support for genetic and genomic studies of fruit trees. In foreign countries, studies have focused on obtaining genomic information of fruit crops and the development of important agronomic trait-related molecular markers, providing a genomic framework for fruit tree breeding. Although Korea does not actively participate in research on the genomics of fruit trees, it is not far behind other countries in terms of technology and is therefore still competitive in research and development. The resequencing of 'Whangkeumbae' and 'Minibae' pears has been performed using the Illumina Hiseq 2000 platform as a part of the Biogreen 21 project, offering novel, rapid methods for identification of molecular marker, such as single nucleotide polymorphisms, insertion-deletions, and simple sequence repeats, through next-generation sequencing (NGS) technology. These NGS-based molecular markers are useful for genetic studies of Asian pears, e.g., for construction of genetic linkage maps, mapping of quantitative trait loci, and marker-assisted selection.
\end{abstract}

Keywords Pyrus spp., pear, next-generation sequencing, molecular marker

\section{INTRODUCTION}

The pear (Pyrus spp.) is one of the most economically important fruit crops worldwide, having been cultivated in Europe and Asia for at least 2000-3000 years, and is commercially grown in all temperate regions, including more than 50 countries (Bell et al. 1996). Approximately 25.2 million tons of pears, harvested from 1.6 million hectares, are produced worldwide each year, making pears the second most important fruit tree in Maloideae after apples (FAO 2013). In Korea, 302,731 tons of pears were produced from 13,127 hectares in 2014 (KOSTAT).

The genus Pyrus belongs to the subfamily Maloideae in the Rosaceae family, sharing a basic chromosome number of $x=17$, which is indicative of a polyploid origin (Bell 1990). The genus Pyrus contains at least 22 primary species; however, only a few species, including $P$. pyrifolia, $P$. ussuriensis, $P$. bretschneideri, $P$. sinkiangensis, and $P$. communis have been used for fruit production (Wu et al. 2013). According to its original distribution, the genus Pyrus is divided into two native groups: occidental and oriental pears (Bailey 1917). Of the occidental pears, $P$. communis is an important cultivated species and has been widely produced throughout Europe, North and South America, Africa, and Australia (Bell 1990; Yamamoto and Chevreau 2009). Of the oriental pears, there are four groups of highly cultivated species: $P$. pyrifolia, $P$. ussuriensis, $P$. bretschneideri, and P. sinkiangensis (Bao 2007). In Asia, $P$. pyrifolia is the main species cultivated in southern and central China, Japan, Korea, and countries of Southeast Asia. In northern China and Japan, $P$. ussuriensis and $P$. bretschneideri are grown for fresh pear production. Various

Received November 19, 2015; Revised November 27, 2015; Accepted November 27, 2015; Published November 30, 2015

*Comesponding author Daeil Kim, dkpomo@cbnu.ac.kr, Tel: +82-43-261-2527, Fax: +82-43-271-0414 
Pyrus species are also used as rootstocks or as ornamentals (Yamamoto and Chevreau 2009).

\section{Genetic characteristics of Pyrus}

Most species of Pyrus are diploid $(2 n=2 x=34)$, with a few triploids ( $2 n=3 x=51)$ or tetraploids $(2 n=4 x=68)$. Pyrus varieties have highly heterozygous genetic backgrounds due to a gametophytic self-incompatibility controlled by a single $S$ locus (Yamamoto and Chevreau 2009). Therefore, estimation of genetic diversity among Pyrus spp. is often challenging. Moreover, as with other self-incompatible woody perennials, pears have a juvenility; therefore, it is not easy for breeders to directly determine genes controlling target traits (Chevreau et al. 1997), and it is nearly impossible to obtain pure lines (Socias i company R 1998). Consequently, fewer genetic studies of pears have been performed than those of other major crops.

\section{Genetic studies of Pyrus spp.}

Phylogenetic analysis of Pyrus varieties has traditionally depended on evaluations of morphological characteristics (Rehder 1915; Kikuchi 1948; Yuan and Du 1980). However, the taxonomy of the genus Pyrus, as evaluated using phenotypic identification, has not been fully determined due to the lack of wild populations, low morphological diversity, lack of differentiating characteristics among species, and widespread cross-ability. Moreover, morphological characteristics are influenced by environmental conditions (Winter and Kahl 1995; Mondini et al. 2009). In addition to morphological markers, several markers have been developed using secondary metabolism, such as isozyme markers, phenolic compounds, pollen ultrastructures, and sugar composition, in order to distinguish among pear species and cultivars (Challice and Westwood 1973; Westwood and Challice 1978; Kajiura et al. 1979; Lin and Shen 1983; Zou et al. 1986; Jang et al. 1992). However, the use of such markers is limited in that their expression is easily influenced by developmental stage and exposure to environmental influences. Moreover, the lack of informative markers limits the utilization of such markers.

Compared with morphological and biochemical markers, molecular markers are practically useful for cultivar identi- fication and characterization because they are influenced by neither variable environmental conditions nor plant phenology and can discriminate among cultivars with similar phenotypes (Belaj et al. 2002). Recently, many researchers have attempted to evaluate genetic diversity in Pyrus spp. using several types of DNA markers, such as amplified fragment length polymorphisms (AFLPs), random amplification of polymorphic DNA (RAPD), and simple sequence repeats (SSRs).

Identification of AFLP markers is a highly sensitive method for detecting polymorphisms used in genetic studies and genetic engineering (Vos et al. 1995). In studies of the genetic diversity of pears, AFLP has several advantages over the RAPD technique, including the capacity for analysis of more loci and increased reproducibility of banding patterns. Dolatowski et al. (2004) and Monte-Corvo et al. (2000) studied the genetic relationships among pear cultivars using AFLP analysis.

RAPD is a polymerase chain reaction (PCR)-based molecular marker technique and was first reported in 1990 (Williams et al. 1990). In RAPD, DNA fragments are amplified in vitro with primers that are designed with random sequences. The arbitrary primers will bind somewhere in the sequence, but it is not certain exactly where (Schierwater and Ender 1993; Schlötterer 2004; Yamamoto and Chevreau 2009). RAPD has been successfully used for identification of the genetic relationships of pear species because of the advantages of being readily employed, requiring small amounts of genomic DNA (Oliveira et al. 1999; Kim et al. 2000; Teng et al. 2001, 2002; Kim and Ko 2004; Lee et al. 2004).

SSRs, also known as microsatellites, are tandem repeats of 2-6 nucleotides. SSR markers have several advantages over other molecular markers, including highly polymorphic features due to variations in length (repeat copy numbers), codominant inheritance, large numbers of alleles per locus, abundance in genomes, requirement for only a small amount of DNA for PCR, and suitability for automation (Weber and May 1989; Moore et al. 1991). More than 100 SSRs have been developed from European (P. communis) and Asian (P. pyrifolia) pears (Yamamoto et al. 2002a, b, c; Sawamura et al. 2004; Fernandez-Fernandez et al. 2006; Inoue et al. 2007). These SSR markers have been applied 
for evaluation of genetic diversity, cultivar identification, and construction of genetic linkage maps (Kimura et al. 2002; Yamamoto et al. 2002c, 2004; Bassil et al. 2005; Volk et al. 2006; Bao et al. 2007).

Single nucleotide polymorphisms (SNPs) are DNA sequence variations caused by single nucleotide changes (i.e., transitions, transversions, deletions, or insertions) among different members in the same species (Vignal et al. 2002). SNPs are highly abundant in plant and animal genomes, but their density varies dramatically from region to region in each genome (Weising et al. 2005). SNP markers have the advantages of being mostly bi-allelic and highly frequent in genomes. Although SNP polymorphism information content (PIC) is lower than that of SSR markers, tens, hundreds, or even thousands of SNPs can be easily used when required. In recent years, SNP markers have been identified in the pear genome sequence using next-generation sequencing (NGS). Yamamoto et al. (2011) developed SNP and SSR markers using random shotgun sequencing to obtain the genome sequence of the Japanese pear P. pyrifolia 'Housui'. Wu et al. $(2013,2014)$ developed SNPs using a combination of BAC-by-BAC and NGS. Montanari et al. (2013) identified 1,096 SNP markers from three European pears (P. communis) using NGS. Terakami et al. (2014) developed a 1,536-SNP bead array without a reference genome sequence from expressed sequence tag (EST) analysis combined with NGS data of Japanese pears.

\section{Genetic linkage maps in Pyrus spp.}

High-density genetic linkage maps are useful for fundamental and applied genetic research. Such maps are usually developed for the purposes of determining the genetic control of specific traits (Folta et al. 2009).

In the genus Pyrus, genetic linkage maps have recently been shown to be sufficiently dense and saturated. Pyrus genetic linkage maps provide information regarding chromosomes that can be used to localized target genes, allow the identification of quantitative trait loci (QTLs), and application of marker-assisted selection (MAS) and marker-assisted breeding (Yamamoto et al. 2007). Several genetic linkage maps and QTL maps of Pyrus have been reported in the Japanese pear ( $P$. pyrifolia) and European pear (P. communis). Iketani et al. (2001) constructed a linkage map for the Japanese pear ( $P$. pyrifolia) and were able to map pear scab and black spot resistance genes. Yamamoto et al. (2002b, 2007) exploited a high-density linkage reference map based on AFLP and SSR markers that could serve as a useful platform for mapping genes and QTLs in pears. Pierantoni et al. $(2004,2007)$ utilized two mapping populations, 'Passe Crassane' $\times$ 'Harrow Sweet' and 'Abbè Fétel' × 'Max Red Bartlett', to identify QTLs for pear scab resistance. Dondini et al. (2004) produced a linkage map of 'Passe Crassane' and 'Harrow Sweet' to identify QTLs for fire blight resistance. Sun et al. (2009) constructed a linkage map of the Chinese pears 'Yali' and 'Jingbaili' to identify QTLs for several vegetative growth traits. Zhang et al. (2013) constructed a genetic linkage map of interspecific hybrid pear 'Bayuehong' (European pear $\times$ Chinese pear) and the Chinese pear 'Dangshansuli' to identify QTLs for several fruit traits using AFLP, SSR, and sequence-related amplified polymorphism (SRAP) markers, along with the S locus for self-incompatibility. Using NGS technology, Montanari et al. (2013) developed SNP-based pear genetic maps in European pears ( $P$. communis), consisting of 857 SNPs. Terakami et al. (2014) developed SNPs without a reference genome sequence from EST analysis combined with NGS data for the Japanese pear 'Housui', and 609 SNP loci were mapped to linkage groups in a genetic linkage map of 'Housui'.

In genetic studies of pears, there is a lack of genetic resources, including molecular markers, making it difficult to construct genetic linkage maps and identify genes controlling target traits. Thus, revealing the location of trait-determining genes on linkage groups and obtaining applicable markers for MAS by the construction of genetic linkage maps and agronomic trait mapping is critical (Yamamoto et al. 2007; Folta et al. 2009; Kale et al. 2012; Wu et al. 2013).

\section{NGS in Pyrus spp.}

Previous methods for identification of molecular markers, such as SSRs, insertions and deletions (InDels), and SNPs, were time- and cost-intensive because of the requirement for preparation and sequencing of genomic libraries and the limited information available regarding nucleotide sequences 
in the pear genome (Squirrell et al. 2003; Eujayl et al. 2004; Iniguez-Luy et al. 2008; Yamamoto and Chevreau 2009; Kale et al. 2012). However, recently developed NGS offer opportunities for high-throughput, time-saving, and costeffective marker development (Mardis 2008; Morozova and Marra 2008). One of the primary advantages of NGS is the identification of sequence data from amplified single DNA fragments, avoiding the need for cloning of DNA fragments. However, the overall high cost of generating high-throughput sequence data remains a limiting factor of NGS technology, although the cost per base is still much lower than that of Sanger sequencing (Ansorge 2009). Another outcome is the capacity for accurate identification of sequences flanking molecular markers (e.g., SSRs, InDels, and SNPs) for use as locus-specific markers for downstream genotyping (Yang et al. 2012).

Our understanding of plant genetics and genomes has reached a new level owing to the use of molecular markers (Nguyen and Wu 2005). Advances in molecular genetics, particularly the development of molecular markers, has improved our capacity for analysis of plant genomes, genetic relationships between cultivars, evolutionary features, and genomic relationships, in addition to facilitating the mapping and tagging of significant trait loci in the genome (Russell et al. 2000; Sjakste et al. 2003; Hamza et al. 2004). With molecular markers, complicated trait loci have been identified and mapped in the genome, and molecular markers tightly linked to important target traits can be used for marker-assisted breeding (Young 1999).

In Pyrus species, whole-genome sequencing has been performed for European pears (P. communis) and Chinese pears (P. bretschneideri) using NGS technology. Wu et al. (2013) reported the draft genome of the pear cultivar 'Suli' using a combination of BAC-by-BAC and NGS. A 512.0 $\mathrm{Mb}$ sequence corresponding to $97.1 \%$ of the estimated genome size of the pear was assembled, and density genetic maps consisting of 2,005 SNPs anchored $75.5 \%$ of the sequence to all 17 chromosomes. Chagné et al. (2014) presented a draft assembly of the genome of the European pear cultivar 'Bartlett'. This genome consisted of 142,083 scaffolds and covered a total of $577.3 \mathrm{Mb}$, representing most of the expected $600 \mathrm{Mb}$ Pyrus genome. The sequencing data of 'Bartlett' pears are available for identification of the genetic control of target traits and for enhancing marker-assisted breeding in Pyrus.

\section{Genome-wide association studies (GWASs) in Pyrus}

GWASs are a powerful approach to identifying novel loci influencing human diseases (Klein et al. 2005). GWASs allow the detection of causal genes or QTLs based on the association between genome-wide markers and phenotypes caused by linkage disequilibrium (LD) between markers or between causal genes and QTLs (Iwata et al. 2013). With the development of high-throughput genotyping technologies, such as DNA chips (Gupta et al. 2008) and NGS (Davey et al. 2011), in addition to associated statistical methods, new genomics-based strategies, such as GWAS, are possible. GWASs are suitable for QTL detection, particularly in long-lived perennials (Oraguzie et al. 2007). However, GWASs are just beginning to be applied to fruit tree species, with only a few species having being analyzed to date (Myles et al. 2011). Yamamoto et al. (2014) conducted GWASs to detect significant associations between 162 markers and nine agronomic traits, including harvest time, resistance to black spot disease, firmness of flesh, fruit size, fruit shape in the longitudinal section, acid content, total soluble solid content, number of spurs, and tree vigor, which are important in pear production. GWASs using the 76 Japanese pear cultivars have detected four markers showing significant associations with three traits: resistance to black spot disease, harvest time, and the number of spurs. In this previous study, significant associations were detected, despite the use of only a few markers and samples for GWAS.

Because few GWASs have been performed in Pyrus species, GWASs will become a powerful tool for identification of associated DNA markers for many important phenotypic traits and will be the most efficient tool for improving pear breeding programs.

\section{Genetic studies of the Asian pear (Pyrus spp.) in Korea}

In Korea, genetic studies of the Asian pear (Pyrus spp.) have been performed as a part of the Biogreen 21 project. 'Whangkeumbae' and 'Minibae' were chosen as the representative cultivars of $P$. pyrifolia and hybrids in Korea. The genomes of 'Whangkeumbae' and 'Minibae' 
were resequenced using the Illumina Hiseq 2000 platform. In 'Whangkeumbae' and 'Minibae', an average of 173.2 million high-quality two-paired-end (PE) reads was generated, corresponding to an average of $17.4 \mathrm{~Gb}$ of sequence (Table 1 ). To align the reads to the reference genome, the Burrows-Wheeler Aligner (BWA) program (Li and Durbin 2009) and Bowtie aligner (Langmead et al. 2009) were applied. The generated sequences of 'Whangkeumbae' and 'Minibae' were aligned to the pear reference genome, i.e., the Chinese pear 'Suli' ( $P$. bretschneideri), and the length was $512 \mathrm{Mb}$ (Wu et al. 2013), with an average of $74.3 \%$ of all PE reads aligning. The reads-mapping region of 'Whangkeumbae' and 'Minibae' was about $444 \mathrm{Mb}$, around 23\% smaller than reference genome.

The SNPs, InDels, and SSRs detected between 'Whangkeumbae' and 'Minibae' using NGS data are shown in Table 2. For SNP detection, NGS data for 'Whangkeumbae' and 'Minibae' were mapped to the reference genome, and a mapped read depth of three or more SNPs was selected through SNP validation and selection. The numbers of total SNPs were 2,711,000, and 2,746,000 in 'Whangkeumbae' and 'Minibae', respectively. Of all SNPs of each cultivar, the numbers of homozygous and heterozygous SNPs were 1,318,000 and 1,393,000 in 'Whangkeumbae' and 1,206,000 and 1,540,000 in 'Minibae', respectively. Polymorphic SNPs were selected based on the same SNP position, and the difference between each cultivar and polymorphic SNPs was 2,510,000. In terms of the distribution of polymorphic SNPs in the intergenic and genic regions, polymorphic SNPs occupied $73.83 \%$ of intergenic regions and $26.17 \%$ of genic regions.

For the detection of InDels, NGS data for 'Whangkeumbae' and 'Minibae' were mapped to the reference genome, and a mapped read depth of three or more InDels was selected through InDel validation and selection. The number of total InDels was 197,000 for both 'Whangkeumbae' and 'Minibae'. The numbers of insertions and deletions were 88,000 and 109,000 in 'Whangkeumbae' and 88,000 and 109,000 in 'Minibae', respectively. Polymorphic InDels were selected based on the same insertion and deletion positions, and the difference between each cultivar and polymorphic InDels was 149,000. In terms of the distribution of polymorphic InDels in the intergenic and genic regions, polymorphic InDels occupied $73.67 \%$ of intergenic regions and $26.33 \%$ of genic regions.

SSRs were detected in the consensus sequence, which was mapped to the reference genome, and sequences of 2-6

Table 1. Illumina Hiseq raw data and reads-mapping region using pear reference genome ${ }^{\mathrm{z})}$ in 'Whangkeumbae' and 'Minibae'.

\begin{tabular}{lccccc}
\hline \hline \multicolumn{1}{c}{ Cultivar } & $\begin{array}{c}\text { Number of } \\
\text { reads }\end{array}$ & $\begin{array}{c}\text { Average length } \\
\text { (bp) }\end{array}$ & $\begin{array}{c}\text { Total length } \\
\text { (bp) }\end{array}$ & $\begin{array}{c}\text { Genome } \\
\text { coverage }^{\mathrm{y})}\end{array}$ & $\begin{array}{c}\text { Reads-mapping } \\
\text { region }^{\mathrm{x})}\end{array}$ \\
\hline Whangkeumbae & $187,595,914$ & 100 & $18,759,591,400$ & $36.64 \times$ & $444,371,531$ \\
Minibae & $158,913,318$ & 100 & $15,891,331,800$ & $31.04 \times$ & $444,569,932$ \\
\hline
\end{tabular}

${ }^{\mathrm{z})}$ Pear reference genome: Pyrus bretschneideri.

${ }^{y)}$ Genome coverage: Total length of cultivar / total length of reference genome.

${ }^{\mathrm{x})}$ Reads-mapping region: (Reads-mapping region / total length of pear reference genome) $\times 100$.

Table 2. Comparative analysis of SNPs, InDels, and SSRs between 'Whangkeumbae' and 'Minibae'.

\begin{tabular}{|c|c|c|}
\hline Cultivar & Whangkeumbae & Minibae \\
\hline Number of total SNPs & $2,711,000$ & $2,746,000$ \\
\hline Number of Polymorphic SNPs & & \\
\hline Number of total InDels & 197,000 & 197,000 \\
\hline Number of Polymorphic InDels & & \\
\hline Number of total SSRs & 75,000 & 75,000 \\
\hline Number of Polymorphic SNPs & & \\
\hline
\end{tabular}


nucleotides in length that were repeated more than five times were selected by SSRs. Polymorphic SSRs were based on differences in the repeated lengths of SSRgenerating regions between each cultivar. The number of total SSRs for 'Whangkeumbae' and 'Minibae' was 75,000, with validation of 1,200 polymorphic SSRs. Thus, these results provide novel, rapid methods for identification of molecular markers using NGS technology. These NGS-based molecular markers will be useful for genetic studies of Asian pears (Pyrus spp.), including for construction of genetic linkage maps, QTL mapping, and MAS in pear breeding efforts.

\section{CONCLUSION}

The importance of the fruit industry and fruit tree breeding has not been recognized fully in Korea, and support for genomic researcher of fruit trees has been poor. Foreign countries are concentrating their efforts on the acquisition of genomic information of fruit crops and the development of important trait-related molecular markers, with the goal of establishing bases for precise fruit tree breeding. Although Korean scientists are not actively researching the genomes of fruit trees, the technologies available in Korea are sufficiently advanced that the country can still be considered competitive in terms of research and development technologies.

In the first phase of the Biogreen 21 project, we performed resequencing in Asian pears (Pyrus spp.) and developed genome-based molecular markers. The second phase, which involves GWAS analysis using a core collection of pear germplasms, is currently under way. The latest genotyping by sequencing (GBS)-based analysis technology can reduce the cost and time of DNA sequence analysis and enhance the efficiency of genetic mapping and the development of molecular markers related to useful traits (Thompson 2014). In addition, GWAS analysis using genotype data developed in GBS and data on useful traits based on phenotypes can overcome difficulties in the genetic analysis of fruit crops through identification of useful genes and development of related molecular markers, thereby enhancing the efficiency of the identification and application of genes related to agriculturally important characters (Huang 2010; Iwata 2013). Through these methods, we may be able to improve our understanding of genetic phenomena in specific fruit crops and among all fruit crops and to enhance the competitiveness of domestic fruit tree breeding through high-efficiency and precise breeding.

\section{ACKNOWLEDGEMENTS}

This work was carried out with the support of "NextGeneration BioGreen21 Program (PJ01105601)” Rural Development Administration, Republic of Korea.

\section{REFERENCES}

Ansorge WJ. 2009. Next-generation DNA sequencing techniques. New Biotechnol. 25: 195-203.

Bailey LH. 1917. Pyrus. Standard cyclopedia of horticulture. vol. 5. Macmillan, New York.

Bao L, Chen K, Zhang D, Cao Y, Yamamoto T, Teng Y. 2007. Genetic diversity and similarity of pear (Pyrus L.) cultivars native to East Asia revealed by SSR (simple sequence repeat) markers. Genet. Resour. Crop Evol. 54: 959-971.

Bassil NV, Postman JD, Neou C. 2005. Pyrus microsatellite markers from genebank sequences ISHS. Acta Hort. 671.

Belaj A, Satovic Z, Rallo L, Trujillo I. 2002. Genetic diversity and relationships in olive (Olea europaea L.) germplasm collections as determined by randomly amplified polymorphic DNA. Theor. Appl. Genet. 105: 638-644.

Bell RL. 1990. Pears (Pyrus). pp. 655-697. In: Moore JN Jr. Ballington JR (eds.). Genetic resources of temperate fruit and nut crops I. ISHS, Wageningen, Netherlands.

Bell RL, Quamme HA, Layne REC, Skirvin RM. 1996. Pears. pp. 441-514. In: Janick J, Moore JN (eds.). Fruit breeding. vol. 1: Tree and tropical fruits. John Willey and Sons, Inc., New York.

Chagné D, Crowhurst RN, Pindo M, Thrimawithana A, Deng C, Ireland H, Fiers M, Dzierzon H, Cestaro A, Fontana P, Bianco L, Lu A, Storey R, Knäbel M, Saeed M, Montanari S, Kim YK, Nicolini D, Larger S, Stefani E, Allan AC, Bowen J, Harvey I, Johnston J, Malnoy M, 
Troggio M, Perchepied L, Sawyer G, Wiedow C, Won K, Viola R, Hellens RP, Brewer L, Bus VGM, Schaffer RJ, Gardiner SE, Velasco R. 2014. The draft genome sequence of European pear (Pyrus communis L. 'Bartlett'). PLOS ONE 9: e92644.

Challice JS, Westwood MN. 1973. Numerical taxonomic studies of the genus Pyrus using both chemical and botanical characters. Bot. J. Linn. Soc. 67: 121-148.

Chevreau E, Leuliette S, Gallet M. 1997. Inheritance and linkage of isozyme loci in pear (Pyrus communis L.). Theor. Appl. Genet. 94: 498-506.

Davey JW, Hohenlohe PA, Etter PD, Boone JQ, Catchen JM, Blaxter ML. 2011. Genome-wide genetic marker discovery and genotyping using next-generation sequencing. Nat. Rev. Genet. 12: 499-510.

Dolatowski J, Nowosielski J, Podyma W, Szymanska M, Zych M. 2004. Molecular studies on the variability of Polish semi-wild pears (Pyrus) using AFLP. J. Fruit Orna. Plant Res. 12: 331-337.

Dondini L, Pierantoni L, Gaiotti F, Chiodini R, Tartarini S, Bazzi, Sansavini S. 2004. Identifying QTLs for fireblight resistance via a European pear (Pyrus communis L.) genetic linkage map. Mol. Breed. 14: 407-418.

Eujayl I, Sledge MK, Wang L, May GD, Chekhovskiy K, Zwonitzer JC, Mian MAR. 2004. Medicago truncatula EST-SSRs reveal cross-species genetic markers for Medicago spp. Theor. Appl. Genet. 108: 414-422.

Fernández-Fernández F, Harvey NG, James CM. 2006. Isolation and characterization of polymorphic microsatellite markers from European pear (Pyrus communis). Mol. Ecol. Notes 6: 1039-1041.

Folta KM, Gardiner SE. 2009. Genetics and genomics of Rosaceae. Springer, New York.

Food and Agriculture Organization of the United Nations. 2013. FAOSTAT-Agriculture. Food and Agriculture Organization of the United Nations.

Gupta PK, Rustgi S, Mir RR. 2008. Array-based high-throughput DNA markers for crop improvement. Heredity 101: 5-18.

Hamza S, Ben HW, Rebai A, Harrabi M. 2004. SSR-based genetic diversity assessment among Tunisian winter barley and relationship with morphological traits. Euphytica 135: 107-118.

Huang X, Wei X, Sang T, Zhao Q, Feng Q, Zhao Y, Li C, Zhu C, Lu T, Zhang Z, Li M, Fan D, Guo Y, Wang A, Wang L, Deng L, Li W, Lu Y, Weng Q, Liu K, Huang T, Zhou T,
Jing Y, Li W, Lin Z, Buckler ES, Qian Q, Zhang Q, Li J, Han B. 2010. Genome-wide association studies of 14 agronomic traits in rice landraces. Nature Genet. 42: 961-967.

Iketani H, Abe K, Yamamoto T, Kotobuki K, Sato Y, Saito T, Terai O, Matsuta N, Hayashi T. 2001. Mapping of disease-related genes in Japanese pear using a molecular linkage map with RAPD markers. Breed. Sci. 51: 179-184.

Iniguez-Luy FL, Voort AV, Osborn TC. 2008. Development of a set of public SSR markers derived from genomic sequence of a rapid cycling Brassica oleracea L. genotype. Theor. Appl. Genet. 117: 977-985.

Inoue E, Matsuki Y, Anzai H, Evans K. 2007. Isolation and characterization of microsatellite markers in Japanese pear (Pyrus pyrifolia Nakai). Mol. Ecol. Notes 7: 445-447.

Iwata H, Hayashi T, Terakami S, Takada N, Sawamura Y, Yamamoto T. 2013. Potential assessment of genome-wide association study and genomic selection in Japanese pear Pyrus pyrifolia. Breed. Sci. 63: 125-140.

Jang JT, Tanabe K, Tamura F, Banno K. 1991. Identification of Pyrus species by peroxidase isozyme phenotypes of flower buds. J. Jpn. Soc. Hortic. Sci. 60: 513-519.

Kajiura I, Yamaki S, Omura M, Akihama T, Machida Y. 1979. Improvement of sugar content and composition in fruits, and classifications of East Asian pears by the principal component analysis of sugar compositions in fruits (in Japanese with English summary). Jpn. J. Breed. 29: $1-12$.

Kale SM, Pardeshi VC, Kadoo NY, Ghorpade PB, Jana MM, Gupta VS. 2012. Development of genomic simple sequence repeat markers for linseed using next-generation sequencing technology. Mol. Breed. 30: 597-606.

Kikuchi A. 1948. Horticulture of fruit trees. Vol. 1. Yokendo, Tokyo.

Kim CS, Lee GP, Han DH, Ryu KH, Lee CH. 2000. Classification and identification of Pyrus pyrifolia using RAPD. J. Kor. Soc. Hortic. Sci. 41: 119-124.

Kim D, Ko KC. 2004. Identification markers and phylogenetic analysis using RAPD in Asian pears (Pyrus spp.). J. Kor. Soc. Hortic. Sci. 45: 194-200.

Kimura T, Zhong SY, Moriyuki S, Kazuo K, Nagao M, Tateki H, Yoshiyuki B, Toshiya Y. 2002. Identification of Asian pear varieties by SSR analysis. Jpn. Breed. Sci. 52: 115-121. 
Klein RJ, Zeiss C, Chew EY, Tsai J-Y, Sackler RS, Haynes C, Henning AK, SanGiovanni JP, Mane SM, Mayne ST, Bracken MB, Ferris FL, Ott J, Barnstable C, Hoh J. 2005. Complement factor $\mathrm{H}$ polymorphism in age-related macular degeneration. Science 308: 385-389.

KOSTAT. 2014. http://kostat.go.kr/portal/korea/kor_nw/2/7/1/ index.board.

Langmead B, Trapnell C, Pop M, Salzberg SL. 2009. Ultrafast and memory-efficient alignment of short DNA sequences to the human genome. Genome Biol. 10: R25.

Lee GP, Lee CH, Kim CS. 2004. Molecular markers derived from RAPD, SCAR, and the conserved 18S rDNA sequences for classification and identification in Pyrus pyrifolia and P. communis. Theor. Appl. Genet. 108: 1487-1491.

Li H, Durbin R. 2009. Fast and accurate short read alignment with Burrows-Wheeler transform. Bioinformatics. 25: 1754-1760.

Lin B, Shen D. 1983. Studies on the germplasmic characteristics of Pyrus by use of isozymic patterns (in Chinese with English summary). Acta Agr. Univ. Zhejiang China 9: 235-243.

Mardis ER. 2008. The impact of next-generation sequencing technology on genetics. Trends Genet. 24: 133-141.

Mondini L, Noorani A, Pagnotta MA. 2009. Assessing plant genetic diversity by molecular tools. Diversity 1: 19-35.

Montanari S, Saeed M, Knäbel M Kim Y, Troggio M, Malnoy M, Velasco R, Fontana P, Won K, Durel C-E, Perchepied L, Schaffer R, Wiedow C, Bus V, Brewer L, Gardiner SE, Crowhurst RN, Chagné D. 2013. Identification of Pyrus single nucleotide polymorphisms (SNPs) and evaluation for genetic mapping in European pear and interspecific Pyrus hybrids. PloS ONE 8, e77022.

Monte-Corvo L, Cabrita L, Oliveira C, Leitao J. 2000. Assessment of genetic relationships among Pyrus species and cultivars using AFLP and RAPD markers. Genet. Resour. Crop Evol. 47: 257-265.

Moore SS, Sargeant LL, King TJ, Mattick JS, Georges M, Hetzel DJS. 1991. The conservation of dinucleotide microsatellites among mammalian genomes allows the use of heterologous PCR primer pairs in closely related species. Genomics 10: 654-660.

Morozova O, Marra MA. 2008. Applications of next-generation sequencing technologies in functional genomics. Genomics 92: 255-264.
Myles S, Boyko AR, Owens CL, Brown PJ, Grassi F, Aradhya MK, Prins B, Reynolds A, Chia J-M, Ware D, Bustamante C, Buckler ES. 2011. Genetic structure and domestication history of the grape. Proc. Natl. Acad. Sci. USA 108: 3530-3535.

Nguyen HT, Wu X. 2005. Molecular Marker Systems for Genetic Mapping. pp. 23-52. In: Meksem K, Kahl G (eds.). The Handbook of Plant Genome Mapping. WILEY-VCH Verlag GmbH \& Co. KGaA, Weinheim, Germany.

Oliveira CM, Mota M, Monte-Corvo L, Goulao L, Silva DL. 1999. Molecular typing of Pyrus based on RAPD markers. Sci. Hortic. 79: 163-174.

Oraguzie NC, Rikkerink EHA, Gardiner SE, De Silva HN. 2007. Association mapping in plants. Springer, New York. p.277.

Pierantoni L, Cho KH, Shin IS, Chiodini R, Tartarini S, Dondini L, Kang SJ, Sansavini S. 2004. Characterisation and transferability of apple SSRs to two European pear F1 populations. Theor. Appl. Genet. 109: 1519-1524.

Pierantoni L, Dondini L, Cho KH, Shin IS, Gennari F, Chiodini R, Tartarini S, Kang S-J, Sansavini S. 2007. Pear scab resistance QTLs via a European pear (Pyrus communis) linkage map. Tree Genet. Genomes 3: 311-317.

Rehder A. 1915. Synopsis of the chinese species of Pyrus. Proc. Amer. Acad. Art and Sci. 50: 225-241.

Russell VJ, Hold GL, Pryde SE, Rehbein H, Quinteiro J, Rey-Mendez M, Sotelo CG, Perez-Martin RI, Santos AT, Rosa C. 2000. Use of restriction fragment length polymorphism to distinguish between salmon species. J. Agric. Food Chem. 48: 2184-2188.

Sawamura Y, Saito T, Takada N, Yamamoto T, Kimura T, Hayashi T, Kotobuki K. 2004. Identification of parentage of Japanese pear 'Housui'. J. Jpn. Soc. Hort. Sci. 73: 511-518.

Schierwater B, Ender A. 1993. Different thermostable DNA polymerases may amplify different RAPD products. Nucleic Acids Res. 21: 4647-4648.

Schlötterer C. 2004. The evolution of molecular markers-just a matter of fashion? Nat. Rev. Genet. 5: 63-69.

Sjakste T, Rashal I, Rashal M. 2003. Inheritance of microsatellite alleles in pedigrees of Latvian barley varieties and related European ancestors. Theor. Appl. Genet. 106: 539-549.

Socias i Company R. 1998. Fruit tree genetics at a turning 
point: the almond example. Theor. Appl. Genet. 96: 588-601.

Squirrell J, Hollingsworth PM, Woodhead M, Russell J, Lowe AJ, Gibby M, Powell W. 2003. How much effort is required to isolate nuclear microsatellites from plants? Mol. Ecol. 12: 1339-1348.

Sun W, Zhang Y, Le W. 2009. Construction of a genetic linkage map and QTL analysis for some leaf traits in pear (Pyrus L.). Front. Agric. China 3: 67-74.

Teng Y, Tanabe K, Tamura F, Itai A. 2001. Genetic relationships of pear cultivars in Xinjiang, China as measured by RAPD markers. J. Hortic. Sci. Biotech. 76: 771-779.

Teng Y, Tanabe K, Tamura F, Itai A. 2002. Genetic relationships of Pyrus species and cultivars native to East Asia revealed by randomly amplified polymorphic DNA markers. J. Am. Soc. Hortic. Sci. 127: 262-270.

Terakami S, Nishitani C, Kunihisa M, Shirasawa K, Sato S, Tabata S, Kurita K, Kanamori H, Katayose Y, Takada N, Saito T, Yamamoto T. 2014. Transcriptome-based single nucleotide polymorphism markers for genome mapping in Japanese pear (Pyrus pyrifolia Nakai). Tree Genet. Genomes 10: 853-863.

Thompson MJ. 2014. High-throughput SNP genotyping to accelerate crop improvement. Plant Breed. Biotech. 2: 195-212.

Vignal A, Milan D, San Cristobal M, Eggen A. 2002. A review on SNP and other types of molecular markers and their use in animal genetics. Genet. Sel. Evol. 34: 275-306.

Volk GM, Richards CM, Henk AD, Reilley AA, Bassil NV, Postman JD. 2006. Diversity of wild Pyrus communis based on microsatellite analyses. J. Am. Soc. Hortic. Sci. 131: 408-417.

Vos P, Hogers R, Bleeker M, Reijans M, Lee TVD, Hornes M, Friters A, Pot J, Paleman J, Kuiper M, Zabeau M. 1995. AFLP: A new technique for DNA fingerprinting. Nucleic Acids Res. 23: 4407-4414.

Weber JL, May PE. 1989. Abundant class of human DNA polymorphism which can be typed using the polymerase chain reaction. Am. J. Hum. Genet. 44: 388-396.

Weising K, Nybom H, Wolff K, Kahl G. 2005. DNA fingerprinting in plants: Principles, methods and applications. $2^{\text {nd }}$ ed, Taylor \& Francis Group.

Westwood MN, Challice JS. 1978. Morphology and surface topography of pollen and anthers of Pyrus species. J. Am.
Soc. Hort. Sci. 103: 28-37.

Williams JGK, Kubelik AR, Livak KJ, Rafalski JA, Tingey SV. 1990. DNA polymorphisms amplified by arbitrary primers are useful as genetic markers. Nucleic Acids Res. 18: 6531-6535.

Winter P, Kahl G. 1995. Molecular marker technologies for plant improvement. World J. Microbiol. Biotechnol. 11: 438-448.

Wu J, Li L-T, Li M, Khan MA, Li X-G, Chen H, Yin H, Zhang S-L. 2014. High-density genetic linkage map construction and identification of fruit-related QTLs in pear using SNP and SSR markers. J. Exp. Bot. doi: 10.1093/jxb/eru311

Wu J, Wang Z, Shi Z, Zhang S, Ming R, Zhu S, Khan MA, Tao S, Korban SS, Wang H, Chen NJ, Nishio T, Xu X, Cong L, Qi1 K, Huang X, Wang Y, Zhao X, Wu J, Deng C, Gou C, Zhou W, Yin H, Qin G, Sha Y, Tao Y, Chen H, Yang Y, Song Y, Zhan D, Wang J, Li L, Dai M, Gu C, Wang Y, Shi D, Wang X, Zhang H, Zeng L, Zheng D, Wang C, Chen M, Wang G, Xie L, Sovero V, Sha S, Huang W, Zhang S, Zhang M, Sun J, Xu L, Li Y, Liu X, Li O, Shen J, Wang J, Paull RE, Bennetzen JL, Wang J, Zhang S. 2013. The genome of the pear (Pyrus bretschneideri Rehd.). Genome Res. 23: 396-408.

Yamamoto T, Chevreau E. 2009. Pear genomics. pp. 163-186. In: Genetics and genomics of Rosaceae. Springer, New York.

Yamamoto T, Kimura T, Shoda M, Ban Y, Hayashi T, Matsuta N. 2002a Development of microsatellite markers in Japanese pear (Pyrus pyrifolia Nakai). Mol. Ecol. Notes 2: 14-16.

Yamamoto T, Kimura T, Shoda M, Imai T, Saito $T$, Sawamura Y, Kotobuki K, Hayashi T, Matsuta N. 2002b. Genetic linkage maps constructed by using an interspecific cross between Japanese and European pears. Theor. Appl. Genet. 106: 9-18.

Yamamoto T, Kimura T, Sawamura Y, Manabe T, Kotobuki K, Hayashi T, Ban Y, Matsuta N. 2002c. Simple sequence repeats for genetic analysis in pear. Euphytica 124: 129-137.

Yamamoto T, Kimura T, Saito T, Kotobuki K, Matsuta N, Liebhard R, Gessler C, van deWeg WE, Hayashi T. 2004. Genetic linkage maps of Japanese and European pears aligned to the apple consensus map. Acta Hort. 663: 51-56.

Yamamoto T, Kimura T, Terakami S, Nishitani C, Sawamura 
Y, Saito T, Kotobuki K, Hayashi T. 2007. Integrated reference genetic linkage maps of pear based on SSRs and AFLPs. Breed. Sci. 57: 321-329.

Yamamoto T, Terakami S, Moriya S, Hosaka F, Kurita K, Kanamori H, Katayose Y, Saito T, Nishitani C. 2011. DNA markers developed from genome sequencing analysis in Japanese pear (Pyrus pyrifolia). Proc. of the XIII Eucarpia Symposium on Fruit Breeding and Genetics 976. pp.477-483.

Yamamoto T, Terakami S, Takada N, Nishio S, Onoue N, Nishitani C, Kunihisa M, Inoue E, Iwata H, Hayashi T, Itai A, Saito T. 2014. Identification of QTLs controlling harvest time and fruit skin color in Japanese pear (Pyrus pyrifolia Nakai). Breed. Sci. 64: 351-361.

Yang T, Bao SY, Ford R, Jia T-J, Guan J-P, He Y-H, Sun X-L, Jiang J-Y, Hao J-J, Zang X-Y, Zong X-X. 2012. High-throughput novel microsatellite marker of faba bean via next generation sequencing. BMC Genomics 13: 602.

Young ND. 1999. A cautiously optimistic vision for markerassisted breeding. Mol. Breed. 5: 505-510.

Yuan F, Du S. 1980. Pears of northwestern China (in Chinese). Shaanxi. Sci. and Technol. Press, Xian, People's Republic of China.

Zhang R-P, Wu J, Li X-G, Khan MA, Chen H, Korban SS, Zhang S-L. 2013. An AFLP, SRAP, and SSR genetic linkage map and identification of QTLs for fruit traits in pear (Pyrus L.). Plant Mol. Biol. Rep. 31: 678-687.

Zou L, Zhang X, Zhang Z, Sun B, Guo S. 1986. Studies on the systematic relationship of some of the species in the genus Pyrus based on pollen grain morphology (in Chinese with English summary). Acta Hort. Sinica 13: 219-224. 